This item was submitted to Loughborough's Research Repository by the author.

Items in Figshare are protected by copyright, with all rights reserved, unless otherwise indicated.

\title{
Causal effects of the United States and Japan on Pacific-Rim stock markets: nonparametric quantile causality approach
}

PLEASE CITE THE PUBLISHED VERSION

https://doi.org/10.1080/00036846.2018.1488062

\section{PUBLISHER}

(c) Taylor \& Francis

\section{VERSION}

AM (Accepted Manuscript)

\section{PUBLISHER STATEMENT}

This is an Accepted Manuscript of an article published by Taylor \& Francis in Applied Economics on 21 Jun 2018, available online: https://doi.org/10.1080/00036846.2018.1488062

\section{LICENCE}

CC BY-NC-ND 4.0

\section{REPOSITORY RECORD}

Balcilar, Mehmet, Rangan Gupta, Duc K. Nguyen, and Mark Wohar. 2019. "Causal Effects of the United States and Japan on Pacific-rim Stock Markets: Nonparametric Quantile Causality Approach". figshare. https://hdl.handle.net/2134/34984. 


\title{
Causal Effects of the United States and Japan on Pacific-Rim Stock Markets: Nonparametric Quantile Causality Approach\#
}

\author{
Mehmet Balcilara,b, Rangan Guptab, Duc Khuong Nguyenc,d, , Mark Wohare \\ a Department of Economics, Eastern Mediterranean University, Famagusta, Turkey \\ ${ }^{b}$ Department of Economics, University of Pretoria, Pretoria, South Africa \\ c IPAG Lab, IPAG Business School, Paris, France \\ d Indiana University School of Public and Environmental Affairs, Bloomington, USA \\ e Department of Economics, University of Nebraska-Omaha, USA and Loughborough University, UK
}

\begin{abstract}
This paper adopts a nonparametric quantile causality approach to examine the causal effects of the U.S. and Japan stock markets on the stock markets of the Pacific-Rim region. This approach allows us to detect not only nonlinear causalities in conditional return (mean) and conditional volatility (variance), but also the asymmetries of causalities under extreme market conditions (bullish vs. bearish states). Our results provide significant evidence of causality in return and volatility at different points of the conditional distributions of returns, with the greater effects from the U.S. than from Japan. Asymmetric quantile causality patterns are particularly pronounced in the case of Japan.
\end{abstract}

JEL Classifications: C32; C58; G10

Keywords: causality in return; causality in variance; equity markets; Pacific-Rim.

${ }^{*}$ Corresponding author: 184, Boulevard Saint-Germain, 75006 Paris, France.

Email addresses: M. Balcilar (mehmet@mbalcilar.net), R. Gupta (Rangan.Gupta@up.ac.za), D.K. Nguyen (uc.nguyen@ipag.fr), and M. Wohar (mwohar@unomaha.edu)

\footnotetext{
\# We would like to thank an anonymous referee for many helpful comments. However, any remaining errors are solely ours.
} 


\section{Introduction}

Over recent decades, financial markets around the world have become more liberalized in terms of effective removal of investment barriers, capital mobility, and financial reforms (Henry, 2000; Bekaert and Harvey, 2000; Ang, 2014). This movement can be seen in markets of both developed and developing countries and is further facilitated by the advances in computer technology and information processing. These factors have not only increased their financial integration (Bekaert and Harvey, 1995; Gerard et al., 2003; Carrieri et al., 2007; Arouri et al., 2012), but also their exposure and sensitivity to shocks, volatility spillovers and contagion effects originating from the rest of the world (Kim and Rogers, 1995; Forbes and Rigobon, 2002; Jayech, 2015). As a result, the linkages and interdependence between national stock markets may have grown stronger and have major implications for corporate investment and financing strategies as well as for international diversification. Strong interdependence would reduce the insulation of the domestic market from any global shock and limit potential gains from international diversifications. Thus, a better understanding of the nature and extent of return and volatility linkages across different financial markets adds to insights on diversification and hedging strategies for investors and appropriate policy actions for regulation bodies and governments.

In this article, we make use of a novel nonparametric quantile causality approach to measure stock market linkages through the implementation of causality-in-quantiles tests. This approach combines the frameworks of $k^{\text {th }}$ order causality of Nishiyama et al. (2011) and quantile causality of Jeong et al. (2012), and hence, can be considered to be a more general version of the former. The causality-in-quantile approach employed in our study to examine the causality across financial markets has several methodological novelties. First, it is robust to misspecification errors as it detects the underlying causality structure between the time series under consideration. This could prove to be particularly important because financial returns commonly display asymmetric and nonlinear dynamics, which the linear causality tests fail to account for. Second, this methodology allows us to test for causality that is likely to exist in the tails of the joint distribution of the variables, i.e. over and above causality-in-mean ( $1^{\text {st }}$ moment), due to high comovement and dependence during turbulent and crisis periods (e.g., Aloui et al., 2011; Herrera and Eichler, 2011). Finally, we are also able to investigate the potential 
causality-in-variance and thereby volatility spillovers. Overall, our framework allows investors and policymakers to design their investment strategies and adopt financial policies with respect to directional causalities in different market states (bear, normal or bull regimes).

At the empirical stage, we particularly focus on the causal effects of the United States and Japan stock markets on 15 other stock markets of the Pacific-Rim region. Given their important role in international financial landscape and trade, changes in the US and Japanese economic and financial policies could have significant influences on the behavior of asset prices around the world. Past studies such as Wei et al. (1995), Ng (2000), Miyakoshi (2003), Kim (2005), Singh et al. (2010), Zhou et al. (2012), and Liu (2014) have documented increased transmission of return and volatility shocks among these markets over recent years. However, the econometric methods they employ do not permit one to separate extreme movements from normal interactions. The evidence on the relative dominance of the United States over Japan in terms of their influences on other markets of the Pacific-Rim region is also mixed.

Our results from the causality-in-quantile tests point out the dominance of the US markets, as compared to Japan, in terms of return and volatility causal interactions with the other stock markets in the Pacific-Rim economies. This finding holds true for all market states in these economies. This finding confirms the results of Chavallier et al. (2018) who use the Diebold and Yilmaz (2009's return spillover measure and find very limited effects of Japanse stock markets on a sample of 11 Pacific Basin stock markets. Meanwhile, an important fact regarding the role of Japan is that we uncover important causality at different quantiles of the conditional distributions of returns and volatility, which are not captured by commonly-used conditional mean-based tests or other approaches such as GARCH-based spillovers, VAR-based shock spillover index, and copula-based dependences. In particular, unlike the US, where causality covers the entire conditional distributions, the Japanese stock market is found to exert return causality in tails on other Pacific-Rim markets, and variance causality around the median of the conditional distribution. The straightforward implication of this result is that investors, portfolio managers and market regulators should care about the extremely negative shocks affecting Japan through reducing their holdings of Japanese-related assets under bearish market conditions. 
The remainder of this paper is organized as follows. Section 2 briefly reviews the related literature. Section 3 introduces the causality-in-quantile approach we employ to test the causality in return and in variance. Section 4 describes the data used and reports the empirical results. Section 5 concludes the paper.

\section{Related literature}

Our work is broadly related to three important strands of the previous literature. The first one focuses on the integration and interactions between markets of developed countries (e.g., Eun and Shim, 1989; Hamao et al., 1990; King et al., 1994). These studies commonly show that developed financial markets are interconnected and that the volatility of the U.S. stock market is transmitted to other developed markets. Subsequent studies have shifted their attention to the relationship between emerging and developed markets, given the increased financial liberalization and global integration (Bekaert and Harvey, 1995; Bekaert and Harvey, 1997; Janakiramanan and Lamba, 1998; Ng, 2000; Pukthuanthong and Roll, 2009). For example, Bekaert and Harvey (1997) document that capital market liberalization often leads to a higher correlation between local and international markets. Based on R-square integration measure, Pukthuanthong and Roll (2009) show a general trend of an increase in market integration for 82 developed and emerging markets over the last three decades, but the patterns of change are countryspecific. Janakiramanan and Lamba (1998), and Ng (2000) report that before 1996, volatility in the US and Japanese equity markets spilled over significantly to the stock markets of the Pacific Basin region (Hong Kong, Korea, Malaysia, Singapore, Taiwan, and Thailand).

The second strand of literature examines the stock market linkages through discriminating between interdependence (in terms of both return and volatility) and contagion. In terms of interdependence, previous studies refer it to a state of normal linkages between markets whereby market linkages are driven by fundamentals (e.g., Kallberg and Pasquariello, 2008; Baele and Inghelbrecht, 2010). It means that stock market linkages can be completely explained by common observed factors that are the result of the cross-market real and financial linkages. Events such as sudden expectation shifts or herding are excluded from this set of common fundamentals, and the high levels of market comovement are often associated with the concept of interdependence. 
Previous research such as Forbes and Rigobon (2002), Corsetti et al. (2005), and Billio and Caporin (2010) typically document evidence of dynamic changes in the fundamentals through time, which explains the time-varying interdependence across international stock markets. Past studies also examine the interdependence of financial markets using linear and nonlinear causality tests in both time and frequency domains (e.g., Bekiros and Marcellino, 2013 for foreign exchange markets; Ding et al., 2014 for real estate and stock markets; Choudhry et al., 2015 for gold and stock markets). It is worth noting that most of these studies have focused on developed markets, and especially interdependence among U.S., Japanese, Asian and major European markets. Some studies have also looked at the interrelations among emerging and developed equity markets (e.g., Samarakoon, 2011; Liu, 2013).

On the other hand, contagion is characterized by strong and sudden changes in the measured market linkages (correlation) following a shock affecting a particular market or a group of markets. This definition, which dates back to Forbes and Rigobon (2002), has also been largely employed in subsequent studies to study the contagion issue in the context of cross-market comovement in returns (e.g., Caporale et al., 2005; Pesaran and Pick, 2007; Baele and Inghelbrecht, 2010). Some studies have generalized this contagion definition to consider the volatility contagion with respect to significant shifts in the second moment of returns (e.g., Chakrabarti and Roll, 2002; Chiang and Wang, 2011; Beirne et al., 2013). An important rationale behind the consideration of volatility contagion is that contagion tests based on return correlation are potentially influenced by the presence of conditional heteroscedasticity in the return series as noted by Loretan and English (2000) and Forbes and Rigobon (2002), which could lead to wrong conclusions about the structural stability of market relations. While most studies show evidence of some interdependence and some contagion, several studies have shown that the standard correlation measures employed in the existing literature on contagion are not able to offer insights about when contagion takes over from interdependence (e.g., Pesaran and Pick, 2007; Dungey et al., 2010). In particular, Dungey et al. (2006) presents some guidance on some of the factors that can either limit or enhance the prospects for contagion type effects. These factors include, among others, the strong economic fundamentals as a device to guard against contagion, the relatively greater sensitivity of emerging markets to contagion effects, and the channel played by developed markets in transmitting shocks around the world. 
When investigating the interdependence and contagious effects among financial markets, the issue of volatility transmission has also received important attention from researchers and practitioners. This gives rise to the third strand of literature which attempts to measure the volatility spillovers across markets, essentially under two perspectives (Weber and Strohsal, 2012): i) volatility spillover as the consequence of potentially correlated information flow; and ii) volatility spillover as reflecting the transmission of uncertainty or valuation insecurity among market participants. Studies that investigate these effects are, among others, Hamao et al. (1990), Lin et al. (1994), Baur and Jung (2006), and Jung and Maderitsch (2014). These studies commonly use the multivariate GARCH, regime switching and stochastic volatility models, and find significant and substantial cross-market volatility spillovers, with the dominant role of the US market as a source for volatility transmission. Departing from the methods above, Diebold and Yilmaz (2009) provide new measures of return and volatility spillovers of international equity markets based on forecast-error variance decompositions in a VAR framework. Diebold and Yilmaz (2011a) discuss the return and volatility spillover among five South American countries using this method, while Yilmaz (2010) used the same to evaluate the return and volatility spillover among major Asian countries. More importantly, Diebold and Yilmaz (2011b) further improve their method in 2009 and use the upgraded model to explore the spillover among major American financial assets including stocks, bonds, foreign exchanges, and commodities from 1999 to 2009, with special attention to the volatility interaction during the subprime mortgage crisis.

Our study contributes to the above-mentioned strands of literature by focusing on market linkages and volatility transmission, but we rather tackle the issue of causality in both return and volatility simultaneously within a causality-in-quantile framework. As stated in the introduction, this approach goes beyond the traditional causality framework as it identifies the existence or non-existence of causality over the entire conditional distribution of returns and volatility, instead of just the conditional mean. Accordingly, it is able to detect causal interactions at various phases of the market, i.e., bear (lower quantiles), normal (median), and bull (upper quantiles). In the process, our approach is inherently a time-varying approach, as it is able to depict causal interactions at various stages of the evolution of the cycles that equity markets go through. In essence, our approach is more informative and general than studies that rely on conditional-mean based approaches, and with our method being a non-parametric model, it is data-driven 
and hence, does not suffer from econometric misspecification due to uncaptured nonlinearity - a feature common to equity markets. The empirical evidence about causality over the entire conditional distributions of returns would thus be important for a number of aspects in finance including the application of multi-market value-at-risk and hedging strategies.

\section{Methodology}

The primary method for inferring causality in financial applications was developed by Granger that takes two time series and determines whether one predicts, or causes, the other. However, it is now common that the conditional mean is a questionable element of analysis if the distributions of variables are non-elliptic or fat tailed as the case of financial returns. In addition, a tail area causality relationship may be quite different from causality relationships based on the center of distribution (see Lee and Yang (2007)). It is well known that the correlations across financial variables depend on the market regime (Lin et al., 1994; Ang and Bekaert, 2002; Longin and Solnik, 2001; Ang and Chen, 2002). In periods with extreme market conditions, financial co-movement across financial variables is stronger as well as contagion and volatility spillovers. Also, the importance of Granger causality in quantile is motivated by their importance for risk management and portfolio diversification (Hong et al., 2009) and the robustness properties of conditional quantile.

Granger causality tests based on conditional mean might be misleading when causality exists only in certain regions of the conditional joint distribution of the variables. This difficulty might be overcome by extending the linear Granger causality test to linear quantile regression. Lee and Yang (2007) developed linear Granger test in quantile, and the tests was shown to detect causal relations that exists in the tails of the conditional distribution. However, the linear causality tests may still fail to detect nonlinear causal relationships. Financial and economic variables do behave highly nonlinearly in the tails of the distribution, while their behavior might be linear in the conditional mean which is an overall summary of the conditional distribution. Nishiyama et al. (2011) developed nonparametric Granger causality tests based on kernel density estimation that overcomes the issues relating to the nonlinearity of the relationship between the variables. To fill the gap in the literature both in terms of the causality in the 
conditional and nonlinearity of the relationship, Jeong et al. (2012) introduces a nonparametric test of Granger causality in quantile based on the kernel density method. The Granger causality in quantile is defined as follows:

1. $x_{t}$ does not cause $y_{t}$ in the $\theta$-quantile with respect to $\left\{y_{t-1}, \ldots, y_{t-p}, x_{t-1}, \ldots, x_{t-p}\right\}$ if

$$
Q_{\theta}\left(y_{t} \mid y_{t-1}, \ldots, y_{t-p}, x_{t-1}, \ldots, x_{t-p}\right)=Q_{\theta}\left(y_{t} \mid y_{t-1}, \ldots, y_{t-p}\right)
$$

2. $x_{t}$ is a prima facie cause $y_{t}$ in the $\theta$-quantile with respect to

$$
\begin{aligned}
& \left\{y_{t-1}, \ldots, y_{t-p}, x_{t-1}, \ldots, x_{t-p}\right\} \text { if } \\
& Q_{\theta}\left(y_{t} \mid y_{t-1}, \ldots, y_{t-p}, x_{t-1}, \ldots, x_{t-p}\right) \neq Q_{\theta}\left(y_{t} \mid y_{t-1}, \ldots, y_{t-p}\right)
\end{aligned}
$$

where $Q_{\theta}\left(y_{t} \mid \cdot\right)$ is the $\theta$ th conditional quantile of $y_{t}$ given ', which depends on $t$ and $0<$ $\theta<1$.

Let us consider $Y_{t-1} \equiv\left(y_{t-1}, \ldots, y_{t-p}\right), X_{t-1} \equiv\left(x_{t-1}, \ldots, x_{t-p}\right), Z_{t}=\left(X_{t}, Y_{t}\right)$, and $F_{y_{t} \mid Z_{t-1}}\left(y_{t} \mid Z_{t-1}\right)$ and $F_{y_{t} \mid Y_{t-1}}\left(y_{t} \mid Y_{t-1}\right)$ which are the conditional distribution function $y_{t}$ given $Z_{t-1}$ and $Y_{t-1}$, respectively.

The conditional distribution $F_{y_{t} \mid Z_{t-1}}\left(y_{t} \mid Z_{t-1}\right)$ is assumed to be absolutely continuous in $y_{t}$ for almost all $Z_{t-1}$. If we denote $Q_{\theta}\left(Z_{t-1}\right) \equiv Q_{\theta}\left(y_{t} \mid Z_{t-1}\right)$ and $Q_{\theta}\left(Y_{t-1}\right) \equiv$ $Q_{\theta}\left(y_{t} \mid Y_{t-1}\right)$, we have,

$F_{y_{t} \mid Z_{t-1}}\left\{Q_{\theta}\left(Z_{t-1}\right) \mid Z_{t-1}\right\}=\theta$, with probability one, i.e., w.p.1.

Consequently, the hypotheses to be tested based on definitions (1) and (2) are

$$
\begin{aligned}
& H_{0}: P\left\{F_{y_{t} \mid Z_{t-1}}\left\{Q_{\theta}\left(Y_{t-1}\right) \mid Z_{t-1}\right\}=\theta\right\}=1 \text { a.s. } \\
& H_{1}: P\left\{F_{y_{t} \mid Z_{t-1}}\left\{Q_{\theta}\left(Y_{t-1}\right) \mid Z_{t-1}\right\}=\theta\right\}<1 \text { a.s. }
\end{aligned}
$$

Jeong et al. (2012) follow Zheng (1998) and reduce the problem of testing quantile restriction to a problem that can be specified as a test of a particular type of mean restriction by using a distance measure $J=\left\{\varepsilon_{t} E\left(\varepsilon_{t} \mid Z_{t-1}\right) f_{Z}\left(Z_{t-1}\right)\right\}$, where $\varepsilon_{t}$ is the regression error term and $f_{Z}\left(Z_{t-1}\right)$ is the marginal density function of $Z_{t-1}$. The regression error $\varepsilon_{t}$ arises from the fact that the null hypothesis in (3) can only be true if only if $E\left[\mathbf{1}\left\{y_{t} \leq Q_{\theta}\left(Y_{t-1}\right) \mid Z_{t-1}\right\}\right]=\theta$ or equivalently $\mathbf{1}\left\{y_{t} \leq Q_{\theta}\left(Y_{t-1}\right)\right\}=\theta+\varepsilon_{t}$, where $\mathbf{1}\{\cdot\}$ is the indicator function. Jeong et al. (2012) specify the distance function as

$$
J=E\left[\left\{F_{y_{t} \mid Z_{t-1}}\left\{Q_{\theta}\left(Y_{t-1}\right) \mid Z_{t-1}\right\}-\theta\right\}^{2} f_{Z}\left(Z_{t-1}\right)\right]
$$


Here, we point out that $J \geq 0$ and the equality holds only under null hypothesis $H_{0}$ in equation (3), while $J>0$ holds only under the alternative $H_{1}$ in equation (4). The result in Fan and Li (1999) establishes that a feasible test statistic based on the distance measure $J$ in equation (5) has the leading term that follows a second order degenerate $U$ statistic and Jeong et al. (2012) show that under the $\beta$-mixing process, the asymptotic distribution of the statistic is asymptotically normal.

Jeong et al. (2012) shows that the feasible kernel-based test statistic has the following form:

$$
\hat{J}_{T}=\frac{1}{T(1-1) h^{2 p}} \sum_{t=p+1}^{T} \sum_{s=p+1, s \neq t}^{T} K\left(\frac{Z_{t-1}-Z_{s-1}}{h}\right) \hat{\varepsilon}_{t} \hat{\varepsilon}_{s}
$$

where $K(\cdot)$ is the kernel function with bandwidth $h$ and $\hat{\varepsilon}_{t}$ is the estimate of the unknown regression error, which is estimated from

$$
\hat{\varepsilon}_{t}=\mathbf{1}\left\{y_{t} \leq \hat{Q}_{\theta}\left(Y_{t-1}\right)\right\}-\theta
$$

where $\hat{Q}_{\theta}\left(Y_{t-1}\right)$ is estimate of the $\theta$ th conditional quantile of $y_{t}$ given $Y_{t-1} \cdot \hat{Q}_{\theta}\left(Y_{t-1}\right)$ can be estimated by the nonparametric kernel method as

$$
\hat{Q}_{\theta}\left(Y_{t-1}\right)=\hat{F}_{y_{t} \mid Y_{t-1}}^{-1}\left(\theta \mid Y_{t-1}\right)
$$

Here, $\widehat{F}_{y_{t} \mid Y_{t-1}}\left(y_{t} \mid Y_{t-1}\right)$ is the Nadarya-Watson kernel estimator and given by

$\hat{F}_{y_{t} \mid Y_{t-1}}\left(y_{t} \mid Y_{t-1}\right)=\frac{\sum_{s=p+1, s \neq t}^{T} L\left(\frac{Y_{t-1}-Y_{s-1}}{h}\right) \mathbf{1}\left(y_{s} \leq y_{t}\right)}{\sum_{s=p+1, s \neq t}^{T} L\left(\frac{Y_{t-1}-Y_{s-1}}{h}\right)}$

with the kernel function $L(\cdot)$ and bandwidth $h$. Jeong et al. (2012) in their analysis, however, confirm that the re-scaled statistic $T h^{p} \hat{J}_{T} / \hat{\sigma}_{0}$ is asymptotically distributed as standard normal, where $\hat{\sigma}_{0}=\sqrt{2} \theta(1-\theta) \sqrt{1 /\left(T(T-1) h^{2 p}\right)} \sqrt{\sum_{t \neq s} K^{2}\left(\left(Z_{t-1}-Z_{s-1}\right) / h\right)}$.

A number of Granger causality tests based on linear parametric models and nonparametric models have been previously proposed. Linear Granger causality tests fail to detect nonlinear causality relationships since they are based on linear covariances and the latter can be easily be zero under nonlinear relationships, even if the underlying variables are dependent. Other tests using nonparametric approach are either based on linear representations or do not consider causality in quantiles. Therefore, these tests based on covariances are not likely to possess good power against certain alternatives. 
The reason is that these tests are constructed under linear representation of the time series, usually the Wold decomposition theorem. However, we only know that the error terms are uncorrelated with the series under study, rather than being independent with it. Our specification through a nonparametric kernel regression does not assume any functional form, therefore it is free of functional misspecification error. The approach is further appealing, because nonparametric test of Granger causality in quantiles is based on the kernel method, which are based on testing conditional quantile restrictions using nonparametric estimation methods and not linear projections. The conditional quantile restriction approach based on the nonparametric (kernel regression) method does not require linear representations and not suffer from functional misspecification errors.

Empirical studies show that volatility transmission (King and Wadhwani, 1990; King et al., 1994; Ng, 2000, Caporale et al. 2005, 2006) across financial markets is observed particularly during market crash periods (Bae and Karolyi, 1994; Claessens, 2001; Bekaert and Ng, 2005; Bartram and Wang, 2005), which is also known as a contagion effect. The recent empirical literature focuses on dependence of financial time series not only on the first moment, but also on the second, third and fourth moments (Friend and Westerfild, 1980; Hwang and Satchell, 1999; Forbes and Rigobon, 2002; Jondeau and Rockinger, 2009). In view of this recent evidence, it is of interest for us also to test for Granger causality in the variance from the US and Japanese stock markets to other Pacific-Rim stock markets. Testing for Granger causality in the second or higher moments has some complications and the procedure for such tests should be carefully defined since rejection of causality in the moment $m$ does not imply non-causality in the moment $k$ for $m<k$.

Following Nishiyama et al. (2011), we generalize the nonparametric Granger quantile causality test to testing for nonparametric Granger quantile causality in variance. Nishiyama et al. (2011) construct nonparametric Granger causality tests using the same density weighted approach in Jeong et al. (2012) and show that density weighted nonparametric tests in higher moments have the same asymptotic normal distribution as the test for causality in first moment, although some stronger moment conditions might be necessary. In order to illustrate the causality in higher order moments let us first consider:

$$
y_{t}=g\left(Y_{t-1}\right)+\sigma\left(X_{t-1}\right) \varepsilon_{t}
$$


where $\varepsilon_{t}$ is a white noise process, and $g(\cdot)$ and $\sigma(\cdot)$ are unknown functions that satisfy certain conditions for stationarity. The specification in equation (10), does not allow predictive power (Granger causality) from $X_{t-1}$ to $y_{t}$, but certainly allows predictive power (in the Granger causality sense) from $X_{t-1}$ to $y_{t}^{2}$. Note that, $\sigma(\cdot)$ is a general nonlinear function and we do not need to explicitly specify squares of $X_{t-1}$ for the specification of the Granger causality in variance. Analogous to quantile causality in mean, we can specify the null and alternative hypotheses for quantile causality in variance as follows:

$$
\begin{aligned}
& H_{0}: P\left\{F_{y_{t}^{2} \mid Z_{t-1}}\left\{Q_{\theta}\left(Y_{t-1}\right) \mid Z_{t-1}\right\}=\theta\right\}=1 \text { almost surely (a.s.) } \\
& H_{1}: P\left\{F_{y_{t}^{2} \mid Z_{t-1}}\left\{Q_{\theta}\left(Y_{t-1}\right) \mid Z_{t-1}\right\}=\theta\right\}<1 \text { a.s. }
\end{aligned}
$$

The feasible test statistic for testing the null hypothesis $H_{0}$ in equation (11) can be obtained by replacing $y_{t}$ in equations (6)-(9) with $y_{t}^{2}$. A problem may arise with the definition of causality given in equation (11) since there may be causality in the second moment (variance) along with the causality in the conditional first moment (mean). We can illustrate this with the following model:

$$
y_{t}=g\left(X_{t-1}, Y_{t-1}\right)+\epsilon_{t}
$$

Higher order quantile causality for a model like in equation (13) can be tested using the following null and alternative hypotheses:

$$
\begin{aligned}
& H_{0}: P\left\{F_{y_{t}^{k} \mid Z_{t-1}}\left\{Q_{\theta}\left(Y_{t-1}\right) \mid Z_{t-1}\right\}=\theta\right\}=1 \text { a.s. } \text { for } k=1,2, \ldots, K \\
& H_{1}: P\left\{F_{y_{t}^{k} \mid Z_{t-1}}\left\{Q_{\theta}\left(Y_{t-1}\right) \mid Z_{t-1}\right\}=\theta\right\}<1 \text { a.s. for } k=1,2, \ldots, K
\end{aligned}
$$

Under this definition, $x_{t}$ Granger causes $y_{t}$ in quantile $\theta$ up to $K$ th moment. For the null specified in equation (14), we can easily construct the test statistic in equation (6) for each $k$. As pointed out by Nishiyama et al. (2011), there is no easy way of combining these statistics into one statistic for the joint null in equation (14), because the statistics constructed for $k=1,2, \ldots, K$ are mutually correlated. One may resort to bootstrap testing approach to compute the correlation and drive the empirical distribution of the statistic for the joint null. The bootstrap approach is computationally too demanding in our case due to more than 6000 observations and already computationally expensive kernel density estimation. 
In order to avoid the high computation cost, we follow the sequential testing approach in Nishiyama et al. (2011) in order to test causality in both models defined in equations (10) and (13). In this approach, we first test for nonparametric Granger causality in the first moment $(k=1)$, but still continue for testing causality in variance even if the non-causality is not rejected. That is, if the null for $k=1$ is not rejected, then there might still be causality in the second moment and, thus, we construct the tests for $k=2$. This approach allows us to test the existence of causality only in variance as well as the causality in the mean and variance successively.

In the empirical implementation of the feasible causality in quantile tests there are three important choices: the bandwidth $h$, the lag order $p$, and the kernel type for the kernels $K(\cdot)$ and $L(\cdot)$ in equations (6) and (9), respectively. In the empirical implementation, we determine the lag order $p$ using the Bayesian Information Criterion (BIC) in a linear bivariate vector autoregressive (VAR) model. ${ }^{1}$ The bandwidth $h$ is selected using the least squares cross-validation method of Rudemo (1982) and Bowman (1984). We use Gaussian kernels for both $K(\cdot)$ and $L(\cdot)$.

\section{Data and Results}

\subsection{Data}

Our data involves the daily MSCI (Morgan Stanley Capital International) stock price indices in US dollars of the various countries under consideration. The sample periods vary across countries over the period from 26 June 1989 to 25 June 2014. Percentage stock market returns are obtained by taking first-differences of the natural logarithms of their price and multiplying by $100 .^{2}$ This transformation ensures the stationarity of the data, which is suitable for further analysis.

Table 1 reports the descriptive statistics of the various stock returns as well as sample periods and number of observations for each country. Over the sampled period, except for Taiwan and Japan, all markets recorded positive mean returns. Some Asian-

\footnotetext{
${ }^{1}$ For the bivariate models involving Japan the optimal lag-length was found to be one, except for the case of Malaysia, where it was two. For the models involving the US, the optimal lag-length was generally one as well, except for the cases of Australia, Canada, South Korea, Singapore, Taiwan and Thailand. This result implies that effect of shocks originating from the US lasts longer when compared to the same originating from Japan, especially for Australia, Canada, South Korea, Singapore, Taiwan and Thailand.

${ }^{2}$ Complete details of the various unit root tests are available upon request from the authors.
} 
Pacific markets (Indonesia, China, South Korea and Thailand) are more volatile than the developed markets. This gives credence to the stylized assertion that developed markets are less risky compared to emerging markets. In all markets, stock returns show asymmetric distribution with a positive kurtosis, and negative skewness, barring the cases of South Korea, Philippines, China and Japan. Hence, not surprisingly the JarqueBera test rejects the null hypothesis of return normality at the $1 \%$ level of significance.

We used the Ljung-Box test with lags one and four to assess the sample autocorrelation. The null hypothesis of no autocorrelation is rejected for all countries except for New Zealand. For Australia and Japan, the null was not rejected for lag one. In addition, the ARCH test was used to determine the presence of conditional heteroscedasticity in the series. For all markets, the null hypothesis of no conditional heteroscedasticity is rejected at $1 \%$ level of significance.

Figure 1 plots the stock returns of the countries involved. Supporting the statistics reported in Table 1, Figure 1 shows volatility switching behavior in all series. All series also have frequent large outlier returns as well as strong volatility clustering behavior. In particular, it can be seen that all stock markets in the Pacific-Rim region experienced extremely large fluctuations during the 2008-2009 global financial crisis. The same pattern of change is observed during the 1997-1998 Asian financial crisis for most of them, except for Australia, Canada, Chile, Colombia and China. These stylized features thus motivate the use of the nonparametric and quantile causality approach in the study as it can capture the causality not only in the center but also in the tails of the return distributions.

\subsection{Empirical Results}

We first present the results obtained from standard and existing Granger causality tests in the conditional mean and variance between stock markets in the United States or Japan with those in other Pacific-Rim economies (Hafner and Herwartz (HH), 2006; and twoversions (robust and non-robust) of Nakatani and Teräsvirta (NT), 2010) for the sake of comparability. Then, we focus on the causal relationships derived from the nonparametric quantile causality test.

The results of the standard causality tests are reported in Table 2. The Granger noncausality test in mean shows that Japan leads the stock markets of Australia, Hong Kong, 
Mexico, Singapore, Taiwan and New Zealand at the 5\% level of significance and better. Causality is detected at the $10 \%$ level for Canada, Chile and Philippines. Not surprisingly, the United States is found to cause strongly all the markets at the $1 \%$ level of significance.

Recognizing the possibility of volatility spillovers, we test for causality in the conditional variance using the two above-mentioned tests. Japan is found to cause the conditional variance in the stock returns of Chile, Columbia, South Korea and Taiwan. Regarding the United States, there is clear evidence of volatility spillovers from the United States to the other markets, based on at least one of the two tests of causality in conditional variance, with the exception of Chile, and surprisingly China.

Although the above standard tests of causality in conditional mean and variance are important, they are less informative than the quantile-based causality test. Indeed, the latter allows us to study causality over the entire conditional distribution of stock returns for a specific country. Hence, this test is able to provide insightful information about the returns and volatility spillovers during different phases (broadly, bearish, normal and bullish) of the stock markets. In this case, the obtained results bring more value to both portfolio managers and investors. Moreover, the nonparametric nature of the quantile causality test is based on a data-driven specification, and does not impose linearity, which is likely to be violated in the presence of structural breaks in the relationships between stock returns, thus leading to spurious conclusions. The results from the quantile causality test in for the returns and volatility is depicted in Figure 2.

As far as causality in stock returns is concerned, Japan is found to cause stock returns for Australia, Columbia, South Korea, Thailand and China over the entire conditional distribution, and primarily at the tails for all other countries except for Taiwan, where the highest causality is found around the median, with some evidence of the same in the tails as well. Note that these Pacific-Rim countries are among the main trading (export and import) partners of Japan, except for Columbia. As far as causality in variance is concerned, there is clear evidence of causality (except for Australia, Hong Kong and Taiwan for which causality is at best weak), primarily around the median (except for Columbia) of the conditional distribution of the variance of stock returns. Clearly, when we compare our results with those reported in Table 2 based on the standard causality tests, we see evidence of the rejection of the null of non-causality to be much stronger for at least some parts of conditional distribution based on our proposed 
quantile causality tests. Moreover, these results enhance our understanding about the role of the Japanese stock market, as compared to studies such as Ng (2000), Miyakoshi (2003), and more recently Chevallier et al. (2018) who only find its limited influence on the Pacific-Rim markets. For example, Ng (2000) finds, from a GARCH-based volatility spillover model, that the return spillover in the six other Pacific Basin markets in the 1980s and the early 1990s is not or very weakly related to Japan's factor.

Next, we turn to the causality impacts from the United States. Except for the case of Columbia where evidence of causality in returns is weak, the US stock markets are found to strongly cause returns for all the other countries over the entire conditional distribution, as shown in Table 3. In addition, when compared to Japan, the influence of United States on stock returns of the other countries is relatively stronger than Japan. Barring the cases of Mexico and Taiwan to some extent, where the causality in variance is restricted to the upper tail of the distribution, the US stock markets are found to cause volatility spillovers in all the markets at all points of the conditional distribution of stock returns volatility of the various economies.

Financial markets may show different causality links during the crises and strong market periods. In order to compare the causality effects on the low and high quantiles (bullish and bearish market states), we examine the test statistics in the low quantiles $\theta=0.10,0.15,0.20$ and the high quantiles $\theta=0.80,0.85,0.90$. We compare the test results in the low quantiles with the test results in the high quantiles to see whether the effects are asymmetric across the low and high market states. Table 3 reports both the causalityin-mean and causality-in-variance test results for the spillovers from the US equity markets to Pacific-Rim equity markets. Causality-in-mean tests in Panel A of Table 3 are all rejected at the $1 \%$ level for all quantiles considered, indicating that return transmission from the US equity markets to Pacific-Rim economies exist strongly in both the low and high quantiles. Therefore, both the bullish and bearish market states of the US equity markets symmetrically spill over to the other Pacific-Rim equity markets.

Panel B of Table 3 reports the causality-in-variance tests for the selected quantiles. Contrary to causality-in-mean tests, causality-in-variance tests for volatility spillover from the US equity markets to Pacific-Rim countries are not symmetric in the low and high quantiles. While volatility transmission exists for all countries except China in the 0.90 -th quantile, volatility transmission does not exist for almost half of the countries 
(Canada, Mexico, Philippines, Singapore, Taiwan, Thailand, China, and New Zeeland) a the 0.10 -th quantile. Therefore, high US equity market volatility spillovers to all Pacific-Rim markets, but low volatility state of the US equity market does not spillover to half of the countries, indicating an asymmetric volatility transmission across the low and high quantiles.

Table 4 reports the test results for the effect of the Japanese equity market on the Pacific-Rim equity markets in the selected low quantiles $\theta=0.10,0.15,0.20$ and the selected high quantiles $\theta=0.80,0.85,0.90$. Panel $A$ of Table 4 shows that the return spillover from Japan to other Pacific-Rim countries is symmetric and significant in both the low and high quantiles. However, the causality-in-variance test results reported in Panel B of Table 4 show that the volatility spillover is asymmetric with stronger transmission of high volatility from Japan to other Pacific-Rim countries. Indeed, there is spillover in the low volatility state from Japan to only five countries (Colombia, Indonesia, South Korea, China, and New Zealand) in the 0.10-th quantile, while the high volatility spillovers to most countries except six countries (Australia, Chile, Mexico, Philippines, Taiwan, and Thailand) in the 0.90-th quantile. In summary, the return spillover from both US and Japan is symmetric and significant across the bullish and bearish markets. On the other hand, we find that volatility spillover from both the US and Japan is asymmetric with strong transmission of the high volatility compared to the low volatility state.

Overall, we find the importance of the US stock markets in terms of returns and volatility spillovers to other Pacific-Rim economies, when compared to Japan. Our results remain intact irrespective of the whether the stock market is in bear, normal or bull regimes in these economies. They also highlight the relevance of considering causality over the entire conditional distribution for the mean and variances of the Pacific-Rim countries, especially for the case of Japan where causality in tails (bear and bull regimes) for the returns and volatility spillover around the median (normal regime) are detected. It is important to note that previous studies such as Janakiramanan and Lamba (1998), and Ng (2000) has dealt with the Pacific-Rim stock markets but they do not distinguish extreme movements from normal ones. Our nonparametric causality-in-quantile approach thus avoid this limitation and ensures the robustness of the results with respect to the presence of nonlinear, asymmetric and extreme linkages. 


\section{Conclusion}

Over the past 15 years, there has been a growing interest among the portfolio managers in the emerging capital markets as they are expected to provide higher asset returns compared to the developed markets. With opening of the economies, the increasing integration between the emerging and the developed markets has led to information and sentiment spillover from one market to another. Evidence on the directional causality from each of these markets would thus help investors to make necessary adjustments for their diversified portfolios and policymakers to prevent potentially harmful and contagious effects of crisis shocks affecting stock markets in the United States and Japan.

In this article, we shed new light on causal interactions among stock markets of the Pacific-Rim region by testing causalities in both return and variance. Using daily dataset covers the period from 25 June 1985 to 25 June 2014, we find evidence to confirm the relative importance of the return and volatility shocks originating from the US and Japanese markets. The impacts from the United States are however greater than those from Japan, a result that corroborates the findings of some previous studies (Wei et al., 1995; Miyakoshi, 2003; Zhou et al., 2012). But in our case, we are able to highlight that this result holds irrespective of whether the markets are in bear, normal, or bull regimes. In other words, diversification opportunities does not exist between the US and the Pacific-Rim countries at any stage of the market cycles. Finally, the presence of causality in tails suggests the usefulness and relevance of our approach, and thus casts doubt on the suitability of the traditional conditional mean-based causality test, which in turn, provides an incomplete picture by relying only on the conditional mean. Our results, based on the causality-in-quantiles approach, have important implications from the point of view of portfolio diversification. While, there are likely to be hardly any diversification gains for US-based investors by investing into the Pacific-Rim stock markets, Japanese investors could still have diversification gains, especially when the Pacific-Rim countries are functioning in their normal mode, given that causality holds only at the tails, i.e., when these markets are functioning in either bear or bull regimes. 


\section{References}

Aloui, R., Ben Aïssa, M.S., Nguyen, D.K., 2011. Global financial crisis, extreme interdependences, and contagion effects: The role of economic structure? Journal of Banking \& Finance 35(1), 130-141.

Ang, A., Bekaert, G., 2002. International asset allocation with regime shifts. Review of Financial Studies 15, 1137-1187.

Ang, A., Chen, J., 2001. Asymmetric correlations in equity portfolios. Journal of Financial Economics 63, 443494

Ang, J.B., 2014. Innovation and financial liberalization. Journal of Banking \& Finance 47, 214-229.

Arouri, M., Nguyen, D.K., Pukthuanthong, K., 2012. An international CAPM for partially integrated markets: Theory and empirical evidence. Journal of Banking and Finance 36, 2473-2493.

Bae, K.-H., Karolyi, G.A., 1994. Good news, bad news and international spillovers of stock returns between Japan and the US. Pacific-Basin Finance Journal 2, 405-438.

Baele, L., Inghelbrecht, K., 2010. Time-varying integration interdependence and contagion. Journal of International Money and Finance 29, 791-818.

Bartram, S.M., Wang, Y.H., 2005. Another look at the relationship between cross-correlation and volatility. Finance Research Letters 2, 75-88.

Baur, D., Jung, R.C., 2006. Return and volatility linkages between the US and the German stock market. Journal of International Money and Finance 25, 598-613.

Beirne, J., Caporale, G.M., Schulze-Ghattas, M., Spagnolo, N., 2013. Volatility spillovers and contagion from mature to emerging stock markets. Review of International Economics 21, 1060-1075.

Bekaert, G, Harvey, C.R., Ng, A., 2005. Market integration and contagion. Journal of Business 78, 39-69.

Bekaert, G., Harvey, C., 1997. Emerging equity market volatility. Journal of Financial Economics 43, 29-77.

Bekaert, G., Harvey, C.R., 1995. Time-varying world market integration. Journal of Finance, 50, 403-444.

Bekaert, G., Harvey, C.R., 2000. Foreign speculators and emerging equity markets. Journal of Finance 55, 565613.

Bekiros, S., Marcellino, M., 2013. The multiscale causal dynamics of foreign exchange markets. Journal of International Money and Finance 33, 282-305.

Billio, M., Caporin, M., 2010. Market linkages, variance spillovers, and correlation stability: empirical evidence of financial contagion. Computational Statistics and Data Analysis 54, 2443-2458.

Bowman, A., 1984. An alternative method of cross-validation for the smoothing of kernel density estimates. Biometrika 71, 353-360.

Caporale, G.M, Cipollini, A., Spagnolo, N., 2005. Testing for contagion: A conditional correlation analysis. Journal of Empirical Finance 12, 476-489.

Caporale, G.M., Pittis, N. , Spagnolo, N. 2006. Volatility transmission and financial crises. Journal of Economics and Finance 30, 376-390.

Carrieri, F., Errunza, V., Hogan, K., 2007. Characterizing world market integration through time. Journal of Financial and Quantitative Analysis, 42, 915-940.

Chakrabarti, R., Roll, R., 2002. East Asia and Europe during the 1997 Asian collapse: a clinical study of a financial crisis. Journal of Financial Markets 5, 1-30.

Chevallier, J., Nguyen, D.K., Siverskog, J., Uddin, G.S., 2018. Market integration and financial linkages among stock markets in Pacific Basin countries. Journal of Empirical Finance 46, 77-92.

Chiang, M.-H., Wang, L.-M., 2011. Volatility contagion: a range-based volatility approach. Journal of Econometrics 165, 175-189.

Choudhry, T., Hassan, S.S., Shabi, S., 2015. Relationship between gold and stock markets during the global financial crisis: Evidence from nonlinear causality tests. International Review of Financial Analysis 41, 247-256.

Claessens, S., Dornbusch, R., Park, Y.S., 2001. Contagion: Why crises spread and how this can be stopped. In: S. Claessens and K. Forbes (eds), International Financial Contagion, Kluwer Academic Publishers, 19-41. 
Corsetti, G., Pericoli, M., Sbracia, M., 2005. Some contagion some interdependence: more pitfalls in tests of financial contagion. Journal of International Money and Finance 24, 1177-1199.

Diebold, F.X., Yilmaz, K., 2009. Measuring financial asset return and volatility spillovers, with application to global equity markets. The Economic Journal 119, 158-171.

Diebold, F.X., Yilmaz, K., 2011a. Equity market spillovers in the Americas. In: Alfaro, R. (Ed.), Financial Stability, Monetary Policy, and Central Banking, vol. 15. Bank of Chile Central Banking Series, Santiago, pp. 199-214.

Diebold, F.X., Yilmaz, K., 2011b. Better to give than to receive: predictive directional measurement of volatility spillovers. International Journal of Forecasting 28, 57-66.

Ding, H., Chong, T.T-l., Park, S.Y., 2014. Nonlinear dependence between stock and real estate markets in China. Economics Letters 124, 526-529.

Dungey, M., Fry, R., Gonzales-Hermosillo, B., Martin, V., 2010. Are all crises alike? Working Paper 10/14. International Monetary Fund, Washington, DC.

Dungey, M., Fry, R., Martin, V., 2006. Correlation, contagion, and Asian evidence. Asian Economic Papers 5, 32-72 (Spring-Summer).

Eun, C.S., Shim, S., 1989. International transmission of stock market movements. Journal of Financial and Quantitative Analysis 24, 241-255.

Fan, Y., Li, Q., 1999. Central limit theorem for degenerate U-statistics of absolutely regular processes with applications to model specification tests. Journal of Nonparametric Statistics 10, 245-271.

Forbes, K., Rigobon, R., 2002. No contagion, only interdependence: Measuring stock market co-movements. Journal of Finance 57, 2223-2261.

Friend, I., Westerfild, R., 1980. Co-skewness and capital asset pricing. Journal of Finance 35, 897-913.

Gerard, B., Thanyalakpark, K., Batten, J., 2003. Are the East Asian markets integrated? Evidence from the ICAPM. Journal of Economics and Business, 55, 585-607.

Hafner, C.M., Herwartz, H., 2006. A Lagrange multiplier test for causality in variance. Economics Letters 93, 137-141.

Hamao, Y., Masulis, R., Ng, V., 1990. Correlations in price changes and volatility across international stock markets. Review of Financial Studies 3, 281-307.

Henry P.B., 2000. Stock market liberalization, economic reform and emerging market equity prices. Journal of Finance 55, 529-563.

Herrera, R., Eichler, S., 2011. Extreme dependence with asymmetric thresholds: Evidence for the European Monetary Union. Journal of Banking \& Finance 35(11), 2916-2930.

Hong, Y., Liu, Y., Wang, S., 2009. Granger causality in risk and detection of extreme risk spillover between financial markets. Journal of Econometrics 150, 271-287.

Hwang, S., Satchell, S.E., 1999. Modelling emerging market risk premia using higher moments. International Journal of Finance and Economics 4, 271-296.

Janakiramanan, S., Lamba, A.S., 1998. An empirical examination of linkages between Pacific-Basin stock markets. Journal of International Financial Markets, Institutions and Money 8, 155-173.

Jayech, S., 2015. The contagion channels of July-August-2011 stock market crash: A DAG-copula based approach. European Journal of Operational Research, In Press, Corrected Proof.

Jeong, K., Härdle, W.K., Song, S., 2012. A consistent nonparametric test for causality in quantile. Econometric Theory 28, 861-887.

Jondeau, E., Rockinger, M., 2009. The Impact of Shocks on Higher Moments. Journal of Financial Econometrics 7, 77-105.

Jung, R.C., Maderitsch, R., 2014. Structural breaks in volatility spillovers between international financial markets: Contagion or mere interdependence? Journal of Banking \& Finance 47, 331-342.

Kallberg, K., Pasquariello, P., 2008. Time-series and cross-sectional excess comovement in stock indexes. Journal of Empirical Finance 15, 481-502. 
Kim, S.J., 2005. Information leadership in the advanced Asia-Pacific stock markets: Return, volatility and volume information spillovers from the US and Japan. Journal of Japanese International Economies, 19, 338-365.

Kim, S.W., Rogers, J.H., 1995. International stock price spillovers and market liberalization: Evidence from Korea, Japan, and the United States. Journal of Empirical Finance 2, 117-133.

King, M., Sentana, E. , Wadhwani, S., 1994. Volatility and links between national stock markets. Econometrica 62, 901-933.

King, M., Wadhwani, S., 1990. Transmission of volatility between stock markets. Review of Financial Studies 3, 5-33.

Lee, T., Yang, W., 2007. Money-income Granger-causality in quantiles. Manuscript, University of California, Riverside.

Lin, W.L., Engle, R.F., Ito, T., 1994. Do bulls and bears move across borders? International transmission of stock returns and volatility. Review of Financial Studies 7, 507-538.

Liu, L., 2013. International stock market interdependence: Are developing markets the same as developed markets? Journal of International Financial Markets, Institutions and Money 26, 226-238.

Liu, L., 2014. Extreme downside risk spillover from the United States and Japan to Asia-Pacific stock markets. International Review of Financial Analysis 33, 39-48.

Longin, F., Solnik, B., 1995. Is the correlation in international equity returns constant: 1960-1990? Journal of International Money and Finance 14, 3-26.

Loretan, M., English, W.B., 2000. Evaluating ‘correlation breakdowns’ during periods of market volatility, Board of Governors of the Federal Reserve System, International Finance Discussion Papers, No. 658.

Miyakoshi, T., 2003. Spillovers of stock return volatility to Asian equity markets from Japan and the US. Journal of International Financial Markets, Institutions and Money, 13(4), 383-399.

Nakatani, T., Teräsvirta, T., 2010. An alternative test for causality in variance in the conditional correlation GARCH models. Mimeo, Stockholm School of Economics.

Ng, A., 2000. Volatility spillover effects from Japan and the US to the Pacific Basin. Journal of International Money and Finance 19, 207-233.

Nishiyama, Y., Hitomi, K., Kawasaki, Y., Jeong, K., 2011. A consistent nonparametric test for nonlinear causality_Specification in time series regression. Journal of Econometrics 165, 112-127.

Okimoto, T., 2014. Asymmetric increasing trends in dependence in international equity markets. Journal of Banking \& Finance 46, 219-232.

Pesaran, M.H., Pick, A., 2007. Econometric issues in the analysis of contagion. Journal of Economic Dynamics and Control 31, 1245-1277.

Pukthuanthong, K., Roll, R., 2009. Global market integration: An alternative measure and its application. Journal of Financial Economics, 94, 214-232.

Rudemo, M., 1982. Empirical choice of histograms and kernel density estimators. Scandinavian Journal of Statistics 9, 65-78.

Samarakoon, L.P., 2011. Stock market interdependence, contagion, and the U.S. financial crisis: The case of emerging and frontier markets. Journal of International Financial Markets, Institutions and Money 21, $724-742$.

Singh, P., Kumar, B., Pandey, A., 2010. Price and volatility spillovers across North American, European and Asian stock markets. International Review of Financial Analysis, 19, 55-64.

Weber, E., Strohsal, T., 2012. The signal of volatility. SFB 649 Discussion Paper.

Wei, K.C.J., Liu, Y.J., Yang, C.C., Chaung, G.S., 1995. Volatility and price change spillover effects across the developed and emerging markets. Pacific-Basin Finance Journal, 3(1), 113-136.

Yilmaz, K., 2010. Return and volatility spillovers among the East Asian equity markets. Journal of Asian Economics 21, 304-313.

Zheng, J., 1998. A consistent nonparametric test of parametric regression models under conditional quantile restrictions. Econometric Theory 14, 123-138. 
Zhou, X., Zhang, W., Zhang, J., 2012. Volatility spillovers between the Chinese and world equity markets, Pacific Basin Finance Journal 20, 247-270. 


\section{Figure 1: Dynamics of Percentage Return Series}
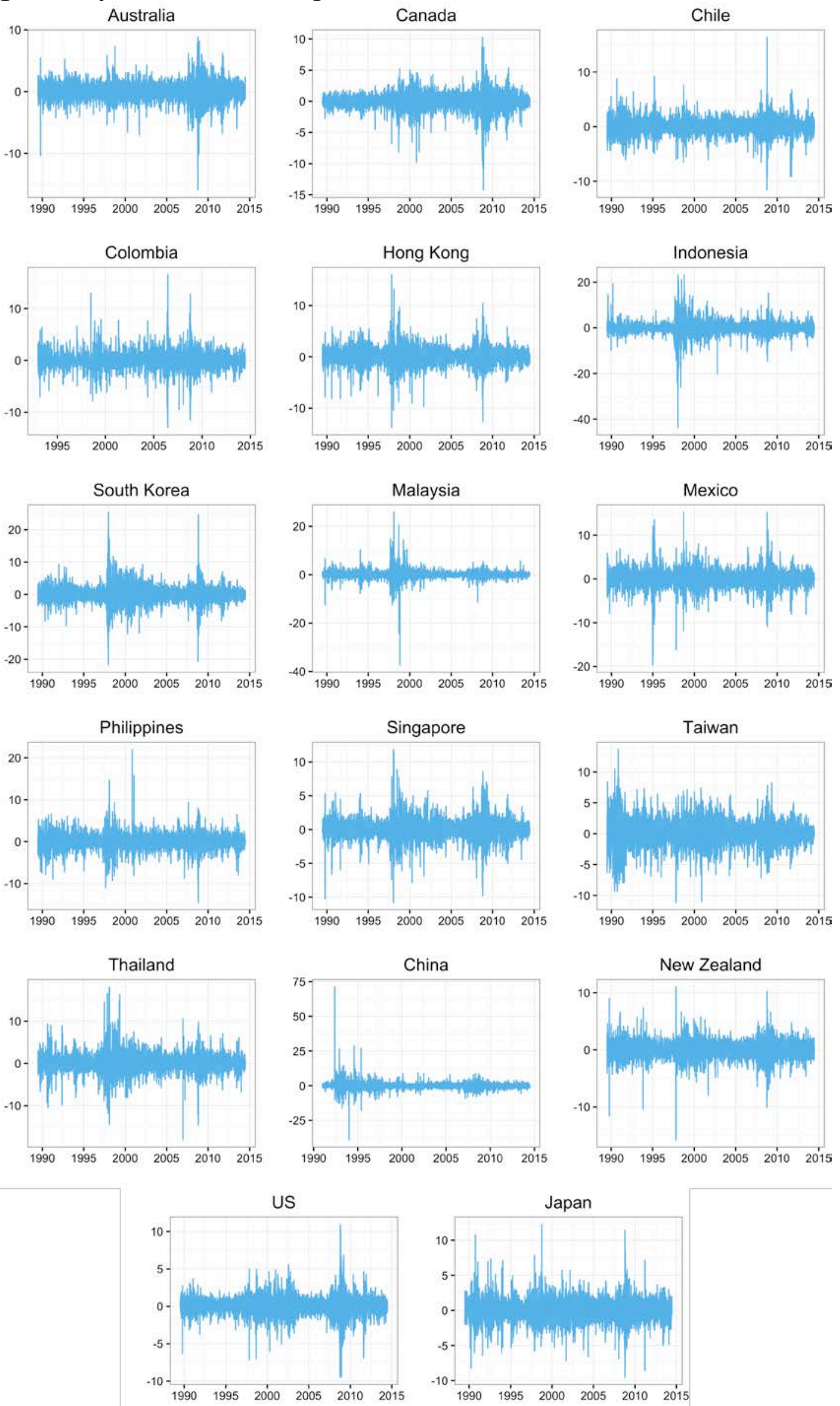

Note: Figure plots the return series (in \%) described in Table 1. See notes to Table 1. 
Figure 2: Causality in mean and variance from the US and Japanese stock markets at various quantiles
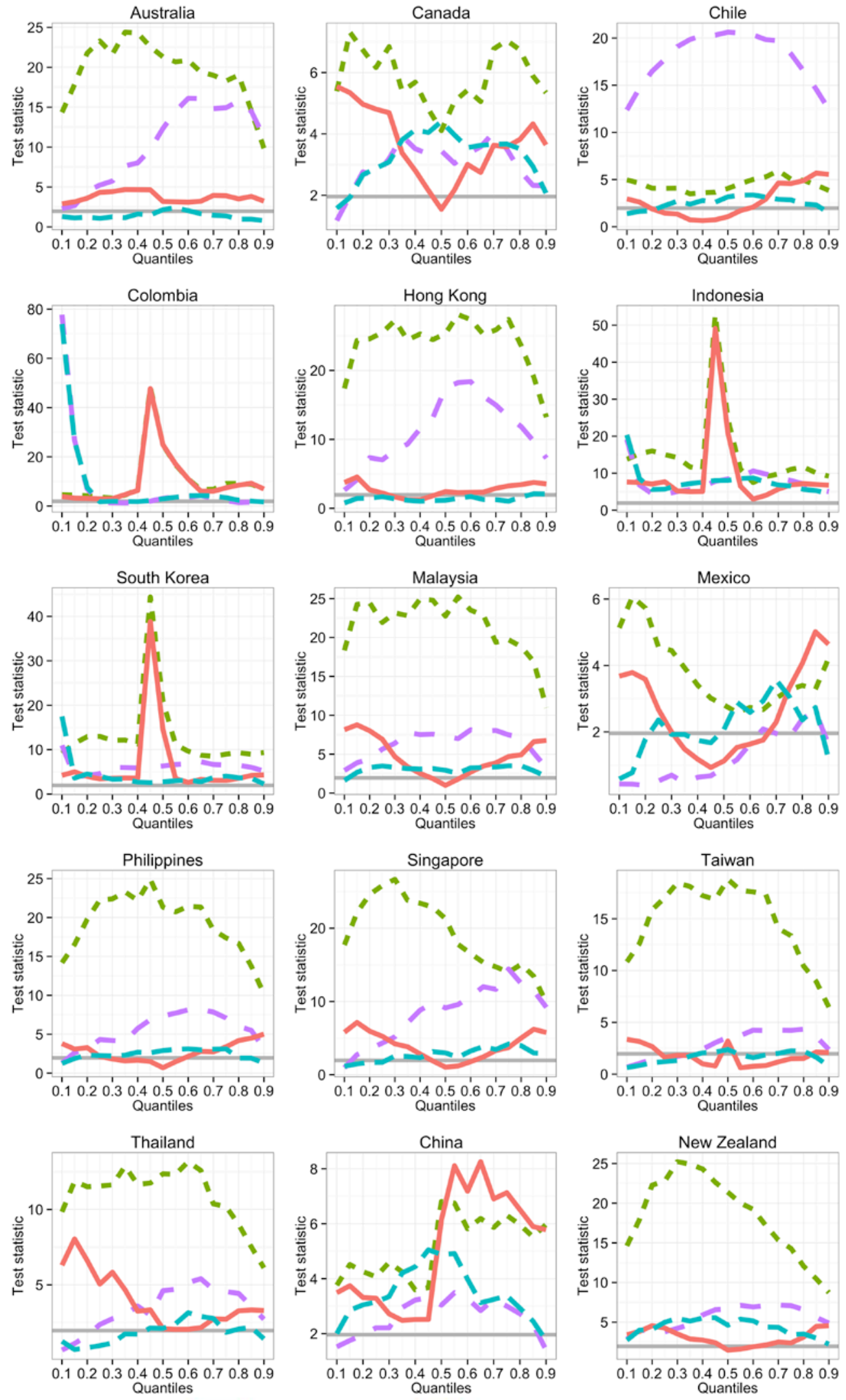

$$
=- \text { Causality in mean from Japan }=\text { Causality in mean from US }=\text { Causality in varaince from Japan }
$$

Note: Figure plots the estimates of the nonparametric causality tests at various quantiles. Horizontal solid line in gray color represents the $5 \%$ critical value. 
Table 1: Descriptive Statistics for the Return Series

\begin{tabular}{|c|c|c|c|c|c|c|c|c|c|c|c|c|c|}
\hline & $n$ & Mean & S.D. & Min & Max & Skewness & Kurtosis & JB & $Q(1)$ & $Q(5)$ & ARCH(1) & $\mathrm{ARCH}(5)$ & Sample Period \\
\hline Australia & 6523 & 0.023 & 1.3893 & -15.9754 & 8.8086 & -0.7114 & 9.5751 & $25488.9690^{* * *}$ & 0.4432 & $13.4906^{* *}$ & $362.6219^{* * *}$ & $1747.2551^{* * *}$ & 06/26/1989-06/25/2014 \\
\hline Canada & 6523 & 0.025 & 1.2562 & -14.2449 & 10.2781 & -0.8091 & 11.7634 & $38350.6270^{* * * *}$ & $27.3967^{* * *}$ & $80.9109^{* * *}$ & $531.2871^{* * *}$ & $1235.0737^{* * *}$ & 06/26/1989-06/25/2014 \\
\hline Chile & 6523 & 0.0377 & 1.3609 & -11.6176 & 16.3603 & -0.0626 & 8.5526 & $19901.2340^{* * * *}$ & $128.0066^{* * *}$ & $143.0752^{* * *}$ & $451.5666^{* * *}$ & $1148.0475^{* * *}$ & 06/26/1989-06/25/2014 \\
\hline Colombia & 5604 & 0.0456 & 1.5672 & -12.9678 & 16.5514 & -0.1193 & 9.6287 & $21681.8610^{* * *}$ & $151.0398^{* * *}$ & $168.6997^{* * *}$ & $400.6645^{* * *}$ & $1034.7584^{* * *}$ & $12 / 31 / 1992-06 / 25 / 2014$ \\
\hline Hong Kong & 6523 & 0.032 & 1.5333 & -13.7697 & 16.0024 & -0.0827 & 8.6829 & $20515.4230^{* * *}$ & $3.6498^{*}$ & $20.2293^{* * *}$ & $742.4159^{* * *}$ & $1068.9440^{* * *}$ & 06/26/1989-06/25/2014 \\
\hline Indonesia & 6523 & 0.0124 & 2.5371 & -43.6718 & 23.2622 & -0.8993 & 30.1629 & $248323.4490^{* * *}$ & $80.0302^{* * *}$ & $111.5507^{* * *}$ & $386.0851^{* * *}$ & $944.7942^{* * *}$ & 06/26/1989-06/25/2014 \\
\hline Malaysia & 6523 & 0.0187 & 1.6396 & -37.3034 & 25.8573 & -1.1165 & 71.9517 & $1409334.4180^{* * *}$ & $60.2154^{* * *}$ & $97.6557^{* * *}$ & $149.9152^{* * *}$ & $229.2240^{* * *}$ & 06/26/1989-06/25/2014 \\
\hline Mexico & 6523 & 0.0505 & 1.8265 & -19.6568 & 15.274 & -0.3987 & 10.1604 & $28253.1870^{* * *}$ & $76.4700^{* * *}$ & $83.9001^{* * *}$ & $159.6305^{* * *}$ & $910.5895^{* * *}$ & 06/26/1989-06/25/2014 \\
\hline Philippines & 6523 & 16 & 1.7166 & -14.4916 & 21.9715 & 0.2685 & 9.877 & $26614.5540^{* * *}$ & $117.5551^{* * *}$ & $127.5428^{* * *}$ & $160.5975^{* * *}$ & $268.7666^{* * *}$ & 06/26/1989-06/25/2014 \\
\hline Singapore & 6523 & 0.0197 & 1.3675 & -10.7608 & 11.8413 & -0.1031 & 7.1833 & $14048.2360^{* * *}$ & $30.0409^{* * *}$ & $33.9799^{* * *}$ & $449.5255^{* * *}$ & $978.8311^{* * *}$ & 06/26/1989-06/25/2014 \\
\hline Taiwan & 6523 & -0.0047 & 1.8757 & -11.1252 & 13.6379 & -0.0416 & 3.4778 & $3293.0190^{* * *}$ & $8.4653^{* * *}$ & $19.8362^{* * *}$ & $199.2356^{* * *}$ & $863.9789^{* * *}$ & 06/26/1989-06/25/2014 \\
\hline Thailand & 6523 & 0.0108 & 2.0256 & -18.0758 & 18.102 & 0.3265 & 9.5923 & $25144.0740^{* * *}$ & $110.8117^{* * *}$ & $123.4350^{* * *}$ & $332.7832^{* * *}$ & $671.9702^{* * *}$ & 06/26/1989-06/25/2014 \\
\hline New Zealand & 6513 & 0.009 & 1.4174 & -15.7574 & 11.0277 & -0.416 & 7.1135 & $13932.1090^{* * *}$ & 1.5171 & 4.6679 & $364.4343^{* * *}$ & $622.5412^{* * *}$ & 07/07/1989-06/25/2014 \\
\hline US & 6513 & 0.0276 & 1.1253 & -9.4695 & 10.9572 & -0.2656 & 9.2041 & $23084.8270^{* * * *}$ & $23.8010^{* * *}$ & $35.7542^{* * *}$ & $289.5629^{* * *}$ & $1283.6646^{* * *}$ & 07/07/1989-06/25/2014 \\
\hline Japan & 6523 & -0.0051 & 1.4592 & -9.5175 & 12.2722 & 0.1132 & 4.4299 & $5353.0470^{* * *}$ & 0.2398 & $20.7413^{* * *}$ & $138.9077^{* * *}$ & $602.5054^{* * *}$ & 06/26/1989-06/25/2014 \\
\hline
\end{tabular}

Note: The table gives the descriptive statistics for log returns. All values are in percent. The sample periods vary across series over 06/26/1989-06/25/2014 with $n$ observations. In addition to the mean, the standard deviation (S.D.), minimum (min), maximum (max), skewness, and kurtosis statistics, the table reports the Jarque-Bera normality test (JB), the Ljung-Box first [Q(1)] and the fourth [Q(5] autocorrelation tests, and the first [ARCH(1)] and the fourth [ARCH(5)] order Lagrange multiplier (LM) tests for the autoregressive conditional heteroscedasticity (ARCH). The asterisks ${ }^{* * *},{ }^{* *}$ and ${ }^{*}$ represent significance at the $1 \%, 5 \%$, and $10 \%$ levels, respectively. 
Table 2: Linear Granger Causality Tests in Conditional Mean and Conditional Variance

\begin{tabular}{|c|c|c|c|c|c|c|c|c|}
\hline \multirow{2}{*}{$\begin{array}{l}\text { Variables } \\
Y / X\end{array}$} & \multicolumn{4}{|c|}{ Japan } & \multicolumn{4}{|c|}{ US } \\
\hline & Granger $F$ & $\mathrm{HH}$ & NT-NR & NT-R & Granger $F$ & $\mathrm{HH}$ & NT-NR & NT-R \\
\hline Australia & $6.5674^{* *}$ & $8.9101^{*}$ & 5.548 & 4.1065 & $1053.0267^{* * *}$ & $274.8102^{* * *}$ & $234.6117^{* * *}$ & $14.5448^{* * *}$ \\
\hline Canada & $3.0452^{*}$ & 0.0171 & 0.4317 & 0.4397 & $68.0612^{* * *}$ & 0.3924 & $8.0656^{*}$ & $12.8896^{* *}$ \\
\hline Chile & $3.4252^{*}$ & $8.3589^{*}$ & $31.1390^{* * *}$ & 5.7051 & $86.1384^{* * *}$ & 1.0497 & 6.0732 & 3.2633 \\
\hline Colombia & $6.5805^{* *}$ & 6.2463 & $21.0931^{* * *}$ & $8.2236^{*}$ & $119.2407^{* * *}$ & $9.0821^{*}$ & $11.9305^{* *}$ & $10.0873^{* *}$ \\
\hline Hong Kong & $12.9414^{* * *}$ & 3.9913 & 7.5218 & $10.2428^{* *}$ & $988.0646^{* * *}$ & $184.5033^{* * *}$ & $188.2755^{* * *}$ & $11.1999^{* *}$ \\
\hline Indonesia & 0.3626 & 2.9198 & 4.1174 & 3.1268 & $279.1438^{* * *}$ & $18.1630^{* * *}$ & $19.3263^{* * *}$ & $13.2812^{* * *}$ \\
\hline South Korea & 0.0175 & $12.6393^{* *}$ & $11.5710^{* *}$ & $10.7479^{* *}$ & $305.9852^{* * *}$ & $84.7462^{* * *}$ & $65.5041^{* * *}$ & $32.6639^{* * *}$ \\
\hline Malaysia & 0.3205 & 3.5074 & 4.2034 & $10.8926^{* *}$ & $393.0107^{* * *}$ & $115.0421^{* * *}$ & $83.1635^{* * *}$ & 2.4695 \\
\hline Mexico & $9.3705^{* * *}$ & 2.7604 & 2.828 & 3.4421 & $64.0700^{* * *}$ & $8.4880^{*}$ & $79.4862^{* * *}$ & $8.1680^{*}$ \\
\hline Philippines & $3.2713^{*}$ & 0.5508 & 0.6006 & 2.4001 & $752.5325^{* * *}$ & $16.9860^{* * *}$ & $9.0397^{*}$ & $14.1321^{* * *}$ \\
\hline Singapore & $17.4069^{* * *}$ & 4.6438 & 3.0423 & 3.2982 & $377.5396^{* * *}$ & $153.0568^{* * *}$ & $408.7667^{* * *}$ & $15.5522^{* * *}$ \\
\hline Taiwan & $8.3280^{* * *}$ & $11.9887^{* *}$ & 7.1234 & 3.2778 & $267.8553^{* * *}$ & $30.5497^{* * *}$ & $43.4444^{* * *}$ & $22.1059^{* * *}$ \\
\hline Thailand & 2.5505 & 2.1793 & 0.6394 & 1.3052 & $173.3315^{* * *}$ & $11.6992^{* *}$ & $11.4893^{* *}$ & $9.5581^{* *}$ \\
\hline China & 0.1103 & 0.8741 & 0.0356 & 0.2735 & $21.0700^{* * *}$ & 0.8646 & 0.6533 & 5.9447 \\
\hline New Zealand & $20.6800^{* * *}$ & 5.8046 & 5.653 & 6.4222 & $1196.1127^{* * *}$ & $197.0514^{* * *}$ & $80.2897^{* * *}$ & $14.6090^{* * *}$ \\
\hline
\end{tabular}

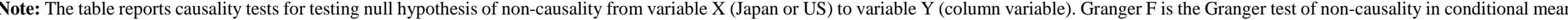

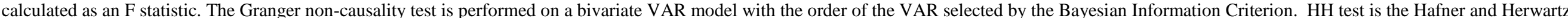

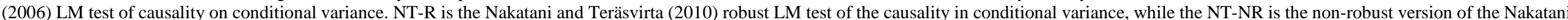

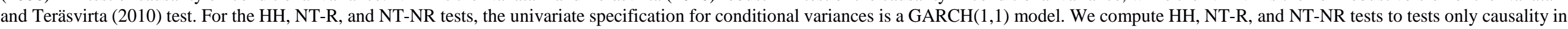
conditional variance from Xvariable (Japan or US) to Y variable. * indicates the rejection of the null hypothesis of non-causality. 
Table 3: Nonparametric Granger Causality-in-Quantiles Tests in Conditional Mean and Conditional Variance for the Causal Effect of US at Selected Quantiles

\begin{tabular}{|c|c|c|c|c|c|c|}
\hline \multirow[b]{4}{*}{ Australia } & \multicolumn{6}{|c|}{ Quantiles $(\theta)$} \\
\hline & 0.10 & 0.15 & 0.20 & 0.80 & 0.85 & 0.90 \\
\hline & \multicolumn{6}{|c|}{ Panel A: Causality in mean test } \\
\hline & $14.353^{* * *}$ & $17.845^{* * *}$ & $21.776^{* * *}$ & $19.018^{* * *}$ & $14.557^{* * *}$ & $9.851^{* * *}$ \\
\hline Canada & $5.390^{* * *}$ & $7.315^{* * *}$ & $6.732^{* * *}$ & $6.743^{* * *}$ & $5.886^{* * *}$ & $5.343^{* * *}$ \\
\hline Chile & $4.966^{* * *}$ & $4.624^{* * *}$ & $4.080^{* * *}$ & $4.923^{* * *}$ & $4.421^{* * *}$ & $3.843^{* * *}$ \\
\hline Colombia & $4.617^{* * *}$ & $4.516^{* * *}$ & $4.148^{* * *}$ & $9.163^{* * *}$ & $8.909^{* * *}$ & $6.770^{* * *}$ \\
\hline Hong Kong & $17.380^{* * *}$ & $24.339^{* * *}$ & $24.579^{* * *}$ & $23.595^{* * *}$ & $19.040^{* * *}$ & $13.201^{* * *}$ \\
\hline Indonesia & $13.782^{* * *}$ & $15.232^{* * *}$ & $16.033^{* * *}$ & $11.642^{* * *}$ & $10.082^{* * *}$ & $9.199^{* * *}$ \\
\hline South Korea & $9.215^{* * *}$ & $11.425^{* * *}$ & $12.915^{* * *}$ & $9.300^{* * *}$ & $8.960^{* * *}$ & $9.340^{* * *}$ \\
\hline Malaysia & $18.339^{* * *}$ & $24.260^{* * *}$ & $24.469^{* * *}$ & $18.836^{* * *}$ & $16.887^{* * *}$ & $10.975^{* * *}$ \\
\hline Mexico & $5.134^{* * *}$ & $6.065^{* * *}$ & $5.731^{* * *}$ & $3.401^{* * *}$ & $3.286^{* * *}$ & $4.210^{* * *}$ \\
\hline Philippines & $14.190^{* * *}$ & $16.538^{* * *}$ & $19.778^{* * *}$ & $16.672^{* * *}$ & $13.745^{* * *}$ & $10.175^{* * *}$ \\
\hline Singapore & $17.708^{* * *}$ & $22.158^{* * *}$ & $24.607^{* * *}$ & $15.076^{* * *}$ & $13.436^{* * *}$ & $9.773^{* * *}$ \\
\hline Taiwan & $10.835^{* * *}$ & $12.606^{* * *}$ & $15.867^{* * *}$ & $10.433^{* * *}$ & $8.939^{* * *}$ & $6.467^{* * *}$ \\
\hline Thailand & $9.842^{* * *}$ & $11.873^{* * *}$ & $11.510^{* * *}$ & $9.006^{* * *}$ & $7.519^{* * *}$ & $6.125^{* * *}$ \\
\hline China & $3.761^{* * *}$ & $4.517^{* * *}$ & $4.256^{* * *}$ & $5.968^{* * *}$ & $5.518^{* * *}$ & $5.976^{* * *}$ \\
\hline \multirow[t]{2}{*}{ New Zealand } & $14.619^{* * *}$ & $17.940^{* * *}$ & $22.284^{* * *}$ & $12.061^{* * *}$ & $10.471^{* * *}$ & $8.724^{* * *}$ \\
\hline & \multicolumn{6}{|c|}{ Panel B: Causality in variance test } \\
\hline Australia & $2.283^{* *}$ & $2.668^{* * *}$ & $4.492^{* * *}$ & $15.779^{* * *}$ & $14.486^{* * *}$ & $11.228^{* * *}$ \\
\hline Canada & 1.174 & $1.983^{* *}$ & $2.763^{* * *}$ & $2.798^{* * *}$ & $2.324^{* *}$ & $2.307^{* *}$ \\
\hline Chile & $12.371^{* * *}$ & $14.699^{* * *}$ & $16.480^{* * *}$ & $16.510^{* * *}$ & $14.567^{* * *}$ & $12.426^{* * *}$ \\
\hline Colombia & $77.803^{* * *}$ & $26.721^{* * *}$ & $6.942^{* * *}$ & 1.438 & 1.617 & $1.924^{*}$ \\
\hline Hong Kong & $2.638^{* * *}$ & $4.156^{* * *}$ & $7.338^{* * *}$ & $11.857^{* * *}$ & $9.701^{* * *}$ & $7.267^{* * *}$ \\
\hline Indonesia & $19.160^{* * *}$ & $6.802^{* * *}$ & $4.464^{* * *}$ & $7.105^{* * *}$ & $5.764^{* * *}$ & $5.009^{* * *}$ \\
\hline South Korea & $10.978^{* * *}$ & $3.859^{* * *}$ & $4.137^{* * *}$ & $6.494^{* * *}$ & $6.005^{* * *}$ & $5.197^{* * *}$ \\
\hline Malaysia & $2.904^{* * *}$ & $3.898^{* * *}$ & $4.413^{* * *}$ & $7.190^{* * *}$ & $5.165^{* * *}$ & $3.224^{* * *}$ \\
\hline Mexico & 0.433 & 0.428 & 0.391 & $2.389^{* *}$ & $2.635^{* * *}$ & 1.616 \\
\hline Philippines & 1.292 & $2.635^{* * *}$ & $3.100^{* * *}$ & $6.027^{* * *}$ & $5.486^{* * *}$ & $3.165^{* * *}$ \\
\hline Singapore & 0.955 & $2.740^{* * *}$ & $3.537^{* * *}$ & $12.462^{* * *}$ & $11.454^{* * *}$ & $9.201^{* * *}$ \\
\hline Taiwan & 0.666 & 1.035 & 1.435 & $4.337^{* * *}$ & $3.631^{* * *}$ & $2.366^{* *}$ \\
\hline Thailand & 0.668 & 1.104 & 1.623 & $4.429^{* * *}$ & $3.579^{* * *}$ & $2.717^{* * *}$ \\
\hline China & 1.521 & $1.754^{*}$ & $1.953^{*}$ & $2.729^{* * *}$ & $2.359^{* *}$ & 1.402 \\
\hline New Zealand & $2.875^{* * *}$ & $3.963^{* * *}$ & $3.942^{* * *}$ & $6.583^{* * *}$ & $5.606^{* * *}$ & $4.871^{* * *}$ \\
\hline
\end{tabular}

Note: The table reports the nonparametric causality-in-quantiles tests at selected quantiles for the causal effect of US. Panel A reports the tests results for the causality in mean while Panel B reports the test results for the causality in variance. ${ }^{*},{ }^{* *}$, and ${ }^{* * *}$ denote significance at $10 \%, 5 \%$, and $1 \%$, respectively. 
Table 4: Nonparametric Granger Causality-in-Quantiles Tests in Conditional Mean and Conditional Variance for the Causal Effect of Japan at Selected Quantiles

\begin{tabular}{|c|c|c|c|c|c|c|}
\hline & \multicolumn{6}{|c|}{ Quantiles $(\theta)$} \\
\hline & 0.10 & 0.15 & 0.20 & 0.80 & 0.85 & 0.90 \\
\hline & \multicolumn{6}{|c|}{ Panel A: Causality in mean test } \\
\hline Australia & $2.899^{* * *}$ & $3.139^{* * *}$ & $3.595^{* * *}$ & $3.509^{* * *}$ & $3.817^{* * *}$ & $3.228^{* * *}$ \\
\hline Canada & $5.544^{* * *}$ & $5.345^{* * *}$ & $4.965^{* * *}$ & $3.819^{* * *}$ & $4.326^{* * *}$ & $3.642^{* * *}$ \\
\hline Chile & $2.953^{* * *}$ & $2.618^{* * *}$ & $1.885^{*}$ & $4.890^{* * *}$ & $5.688^{* * *}$ & $5.544^{* * *}$ \\
\hline Colombia & $3.891^{* * *}$ & $3.223^{* * *}$ & $3.116^{* * *}$ & $8.504^{* * *}$ & $9.232^{* * *}$ & $6.944^{* * *}$ \\
\hline Hong Kong & $3.748^{* * *}$ & $4.538^{* * *}$ & $2.690^{* * *}$ & $3.444^{* * *}$ & $3.755^{* * *}$ & $3.544^{* * *}$ \\
\hline Indonesia & $7.643^{* * *}$ & $7.488^{* * *}$ & $7.091^{* * *}$ & $7.192^{* * *}$ & $6.967^{* * *}$ & $6.775^{* * *}$ \\
\hline South Korea & $4.217^{* * *}$ & $4.992^{* * *}$ & $3.971^{* * *}$ & $3.539^{* * *}$ & $4.193^{* * *}$ & $4.309^{* * *}$ \\
\hline Malaysia & $8.152^{* * *}$ & $8.774^{* * *}$ & $8.015^{* * *}$ & $4.922^{* * *}$ & $6.609^{* * *}$ & $6.774^{* * *}$ \\
\hline Mexico & $3.678^{* * *}$ & $3.788^{* * *}$ & $3.584^{* * *}$ & $4.067^{* * *}$ & $5.017^{* * *}$ & $4.639^{* * *}$ \\
\hline Philippines & $3.796^{* * *}$ & $3.091^{* * *}$ & $3.272^{* * *}$ & $4.193^{* * *}$ & $4.503^{* * *}$ & $5.010^{* * *}$ \\
\hline Singapore & $5.796^{* * *}$ & $7.132^{* * *}$ & $5.944^{* * *}$ & $5.005^{* * *}$ & $6.204^{* * *}$ & $5.765^{* * *}$ \\
\hline Taiwan & $3.360^{* * *}$ & $3.148^{* * *}$ & $2.661^{* * *}$ & 1.514 & $2.130^{* *}$ & $2.090^{* *}$ \\
\hline Thailand & $6.296^{* * *}$ & $8.041^{* * *}$ & $6.614^{* * *}$ & $3.277^{* * *}$ & $3.331^{* * *}$ & $3.297^{* * *}$ \\
\hline China & $3.488^{* * *}$ & $3.744^{* * *}$ & $3.318^{* * *}$ & $6.514^{* * *}$ & $5.901^{* * *}$ & $5.779^{* * *}$ \\
\hline \multirow[t]{2}{*}{ New Zealand } & $3.414^{* * *}$ & $3.833^{* * *}$ & $4.545^{* * *}$ & $3.116^{* * *}$ & $4.458^{* * *}$ & $4.547^{* * *}$ \\
\hline & \multicolumn{6}{|c|}{ Panel B: Causality in variance test } \\
\hline Australia & 1.292 & 1.126 & 1.228 & 0.968 & 0.965 & 0.787 \\
\hline Canada & 1.572 & $1.928^{*}$ & $2.668^{* * *}$ & $3.516^{* * *}$ & $2.940^{* * *}$ & $2.068^{* *}$ \\
\hline Chile & 1.387 & 1.628 & $1.716^{*}$ & $2.413^{* *}$ & $2.312^{* *}$ & 1.474 \\
\hline Colombia & $73.982^{* * *}$ & $26.456^{* * *}$ & $7.560^{* * *}$ & $2.368^{* *}$ & $2.031^{* *}$ & $1.676^{*}$ \\
\hline Hong Kong & 0.777 & 1.439 & 1.482 & 1.640 & $2.105^{* *}$ & $2.074^{* *}$ \\
\hline Indonesia & $20.369^{* * *}$ & $8.569^{* * *}$ & $5.605^{* * *}$ & $5.626^{* * *}$ & $5.285^{* * *}$ & $4.478^{* * *}$ \\
\hline South Korea & $17.492^{* * *}$ & $3.619^{* * *}$ & $4.512^{* * *}$ & $3.668^{* * *}$ & $3.584^{* * *}$ & $2.270^{* *}$ \\
\hline Malaysia & 1.628 & $2.664^{* * *}$ & $3.289^{* * *}$ & $3.506^{* * *}$ & $2.868^{* * *}$ & $2.137^{* *}$ \\
\hline Mexico & 0.582 & 0.776 & $1.786^{*}$ & $2.360^{* *}$ & $2.736^{* * *}$ & 1.196 \\
\hline Philippines & 1.243 & $1.884^{*}$ & $2.325^{* *}$ & $1.934^{*}$ & $1.929^{*}$ & 1.301 \\
\hline Singapore & 1.149 & 1.475 & $1.678^{*}$ & $3.964^{* * *}$ & $2.969^{* * *}$ & $2.884^{* * *}$ \\
\hline Taiwan & 0.633 & 0.832 & 1.106 & $2.217^{* *}$ & 1.634 & 0.766 \\
\hline Thailand & 1.254 & 0.708 & 0.822 & $2.067^{* *}$ & $2.173^{* *}$ & 1.417 \\
\hline China & $2.001^{* *}$ & $2.855^{* * *}$ & $3.046^{* * *}$ & $2.930^{* * *}$ & $2.459^{* *}$ & $1.753^{*}$ \\
\hline New Zealand & $2.732^{* * *}$ & $3.993^{* * *}$ & $4.073^{* * *}$ & $3.514^{* * *}$ & $2.993^{* * *}$ & $2.214^{* *}$ \\
\hline
\end{tabular}

Note: The table reports the nonparametric causality-in-quantiles tests at selected quantiles for the causal effect of Japan. Panel A reports the tests results for the causality in mean while Panel B reports the test results for the causality in variance. ${ }^{*},{ }^{* *}$, and ${ }^{* * *}$ denote significance at $10 \%, 5 \%$, and $1 \%$, respectively. 